\title{
AS RELAÇÕES ENTRE O PROÊMIO DA ÉTICA EUDÊMIA E O RESTANTE DA OBRA - UMA DISCUSSÃO A PARTIR DA ANÁlISE DE ÉTICA EUDÊMIA I- $7^{1,{ }_{2}}$
}

\section{Raphael Zillig (UFRGS) ${ }^{3}$}

rzillig@gmail.com

Resumo: A investigação de Aristóteles acerca da felicidade na Ética Eudêmia tem seu início efetivo em EE I 7, uma vez que os primeiros seis capítulos da obra são descritos como um proêmio. Diante disso, surge uma questão acerca da natureza das relações entre o proêmio e o texto principal. Deve-se tomar o proêmio como desempenhando uma função meramente introdutória à investigação propriamente dita ou é possível que os argumentos desenvolvidos na investigação da EE dependam do que fora exposto no proêmio? Acreditamos que uma análise do argumento de EE I 7 possa lançar alguma luz sobre essa questão. Sustentaremos que esse argumento, ao menos, retira uma de suas premissas do proêmio e, portanto, não pode progredir sem basear-se na porção introdutória do texto.

Palavras-chave: Aristóteles; método; felicidade; telos.

Ao final de Ética Eudêmia I 7, Aristóteles mostra que não se deve tomar a felicidade como o maior dos bens humanos sem mais, mas como o maior dos bens realizáveis para o homem. $\mathrm{O}$ argumento não apresenta especial dificuldade, mas sua posição no interior de EE I torna-o merecedor de

\footnotetext{
1 Recebido em: 28-07-2014/Aprovado: 06-11-2014/Publicado on-line: 17-02-2015.

${ }^{2} \mathrm{O}$ presente trabalho foi realizado com apoio da CAPES, entidade do Governo Brasileiro voltada para a formação de recursos humanos.

3 Raphael Zillig é Professor Adjunto na UFRGS, Porto Alegre, RS, Brasil. Desde 2012, é bolsista de produtividade em pesquisa do CNPq nível 2 e pesquisador colaborador da Universidade Estadual de Campinas.
} 
atenção. Os seis primeiros capítulos do livro são dedicados à exposição de um proêmio ${ }^{4}$, de modo que a investigação propriamente dita inicia-se a partir de EE I 7. O argumento em questão, portanto, é o primeiro movimento da investigação que começa após o encerramento da introdução.

Estando assim situado, o argumento torna-se um elemento importante no exame das relações entre a investigação propriamente dita e o proêmio. É certo que algumas tarefas realizadas nos primeiros capítulos sejam próprias de uma exposição que é prévia à investigação. Não é de todo claro, no entanto, que a importância dos capítulos iniciais para o desenvolvimento da pesquisa sobre a felicidade seja meramente a de uma preparação preambular.

\section{O PROÊMIO DA ÉTICA EUdÊMIA ${ }^{5}$}

$\mathrm{Na}$ porção inicial da obra, Aristóteles esclarece que os objetivos do estudo não se limitam à compreensão teórica da felicidade, devendo contribuir para sua aquisição. Lá também são apresentadas as questões fundamentais para a investigação e as principais características do método apropriado. A exposição desses pontos destina-se a familiarizar o leitor com o foco e o procedimento que serão adotados no desenvolvimento da investigação. Isso confere ao trecho de EE I 1-6 algumas das características que Aristóteles atribui ao prooimion na Retórica (especialmente

\footnotetext{
4 Os limites do proêmio são demarcados na primeira linha de EE I 7 (peprooimismenôn de kai toutôn, 1217a18).

5 Olof Gigon (1971) elaborou uma análise detalhada do proêmio sem examinar, contudo, as relações entre o proêmio e o restante do texto.
} 
em III 14). Tal como lá descrito, o proêmio corresponde a uma preparação para o que virá em seguida (1414b21) e deve, sobretudo, esclarecer o fim com vistas ao qual é feito o discurso (1415a23-24). Além de executar as tarefas mencionadas, no entanto, os capítulos iniciais da EE também apresentam opiniões reputadas sobre o tema da investigação. Entre outras posições, Aristóteles expõe três concepções tradicionais da felicidade, que é compreendida como uma vida voltada ou à virtude ou à contemplação ou ao prazer $^{6}$. O papel dessas concepções acerca da boa vida na investigação gerou uma discussão entre os intérpretes que evoca uma questão de maior alcance acerca das relações entre os capítulos iniciais e o restante da EE.

No âmbito de uma comparação entre a EE e o Protréptico, Werner Jaeger sugeriu que as três vidas (juntamente com o uso peculiar que Aristóteles faz da noção de phronêsis no início da EE) desempenham um papel decisivo na determinação da estrutura do sistema ético da EE (JAEGER 1948, 235-238). Essa hipótese sugere que o proêmio estabelece elementos determinantes para o desenvolvimento da investigação e não se limita a preparar o leitor para o que está por vir. Contra Jaeger, John Cooper sustentou que "o estudo das três vidas não fornece a estrutura da Ética Eudêmia mais do que o faz com respeito à Nicomaqueia " (COOPER 1975, 145, n. 1). Em seu arrazoado, Cooper enfatizou a disparidade entre a concepção de eudaimonia desenvolvida ao longo da EE e as três concepções tradicionais da boa vida. A partir dessa

\footnotetext{
6 O núcleo da exposição acerca das três vidas está entre EE I 4 e EE I 5, mas os bens que constituem o objeto de busca em cada uma dessas concepções são introduzidos já em EE I 1, 1214a30-b6.
} 
perspectiva, seria possível sugerir que a exposição acerca das três vidas insere-se no objetivo de assegurar a atenção do leitor, cujo interesse seria atraído pelas compreensões da boa vida que lhe são familiares. Esse tipo de recurso é dito ser externo ao discurso (Ret. III 14, 1415b5) e se EE I 1-6, além de apresentar os objetivos e o método da investigação, limita-se a preparar o leitor para o que virá a seguir, sua função seria adequadamente descrita como correspondendo apenas a uma introdução para o texto que começa em EE I 7.

Com efeito, a Retórica indica que as características a partir das quais um texto é identificado como proêmio não interferem diretamente no andamento da argumentação do texto principal. Além de ser apresentado como uma preparação para o que segue (1414b21), o proêmio é expressamente distinguido da parte do texto que comporta convencimento (pistis - 1414b7-12) e pode mesmo afastarse do tópico central do discurso (1414b29). Ainda que o proêmio deva compor uma unidade textual com o restante da obra, ele assemelha-se às exibições que os flautistas fazem para mostrar suas habilidades antes de executar a peça programada (1414b21-26).

Um texto, no entanto, pode bem desempenhar a função preparatória que é típica de um proêmio e, adicionalmente, estabelecer elementos determinantes para o andamento da argumentação central. Isso pode ocorrer sobretudo quando a exposição de elementos do texto central for capaz de cumprir os objetivos preparatórios do proêmio. Esse duplo papel pode ser encontrado na interpretação que Anthony Kenny (1978, 194-214) propôs para a apresentação das três vidas nos capítulos iniciais da EE. As concepções tradicionais da boa vida são conhecidas 
do leitor, de modo que, ao evocá-las, Aristóteles prepara-o para a discussão acerca da felicidade. Para Kenny, contudo, as três vidas têm, adicionalmente, um papel fundamental no argumento central: elas correspondem ao ponto de partida da investigação propriamente dita e estabelecem o plano da obra como um todo (KENNY 1978, 195). Em última análise, a EE teria por objetivo esclarecer adequadamente essas opiniões, cuja exposição desempenha o papel de uma premissa para o argumento central (KENNY 1978, 207).

Neste trabalho, nosso interesse não está nas três vidas, mas na questão que emerge do debate que se estabelece em torno delas, ou seja, a questão acerca da relação entre o proêmio e o restante da EE. A argumentação desenvolvida na investigação central da EE depende, de alguma forma, do que foi exposto no proêmio ou ela deve ser compreendida independentemente dos capítulos iniciais, aos quais caberia apenas preparar o caminho para o texto central?

Essa questão está no foco de nossa abordagem do argumento de EE I 7. Sua análise não pode, por si só, fornecer a solução do problema. No entanto, uma vez que se trata do primeiro capítulo da investigação propriamente dita, não seria surpreendente que o argumento ali exposto fosse capaz de dar pistas valiosas para a resolução da questão.

\section{O MÉTODO DA INVESTIGAÇÃO PROPRIAMENTE DITA}

O proêmio encerra-se com um conjunto de considerações metodológicas em I 6 . Essas considerações devem caracterizar o tratamento que a felicidade receberá na 
investigação propriamente dita, em oposição ao que ocorre nos capítulos iniciais.

O núcleo do método proposto corresponde à diretriz segundo a qual a investigação deve partir da análise de phainomena ("aquilo que é manifesto") que compreendem o que é verdadeiro sobre o assunto sob investigação, mas não o apresentam de modo claro. A investigação, portanto, avança à medida que se torna claro o que existe de verdadeiro nos phainomena (1216b26-35).

Essa diretriz metodológica não é exclusiva da investigação sobre o bem humano - ao contrário, ela é apresentada alhures como uma norma a ser seguida em toda investigação rigorosa (ver Primeiros Analíticos I 30 46a17-22) e há fartos exemplos de sua aplicação nas obras de caráter científico de Aristóteles. $\mathrm{O}$ que há de específico a cada investigação depende da natureza dos phainomena relevantes ${ }^{7}$.

Proceder a uma análise detalhada do sentido técnico de phainomenon em Aristóteles excederia nossos propósitos neste trabalho. Limitamo-nos a uma breve remissão à discussão que se desenvolveu na segunda metade do século XX e que partiu do exame de uma compreensão hoje superada do termo. Tal compreensão resulta da generalização do papel dos phainomena em certos textos de ciência natural de Aristóteles. De acordo com essa interpretação, os phainomena corresponderiam a observações empíricas. A influência dessa compreensão

\footnotetext{
7 Não se trata, no entanto, de uma posição unânime. Owen (1961) e Irwin (1987) não etendem que o método descrito no texto dos Primeiros Analíticos aplique-se ao contexto da ética. Tal interpretação recebeu uma resposta de Nussbaum (1986), cuja posição, no entanto, cria novos problemas (cf. WIANS 1992). A nosso juízo, as interpretações de Owen e Irwin são adequadamente respondidas por Cleary (1994).
} 
(adequada na leitura dos textos de ciência natural) sobre a interpretação das obras éticas de Aristóteles pode ser percebida a partir do fato que D. W. Ross traduz ocorrências de phainomena na Ética Nicomaqueia por "observed facts" (ver, por exemplo, sua tradução de EN 1145b3).

A partir do exame da Física de Aristóteles e de Ética Nicomaqueia VII 1, 1145b2-6 ${ }^{8}$, G. E. L. Owen (1961) mostrou que os phainomena não se limitam às observações empíricas, correspondendo em certos contextos a endoxa ("opiniões reputáveis") e a legomena ("coisas ditas" de modo geral, abrangendo de padrões identificáveis no uso da língua a ditos tradicionais).

O sentido de phainomenon identificado por Owen é particularmente esclarecedor das ocorrências do termo nas obras de ética. $\mathrm{Na} \mathrm{EE}$, os phainomena correspondem a opiniões fundamentais sobre a felicidade, que são tomadas como exprimindo de modo obscuro as verdades cuja expressão clara deve surgir do desenvolvimento da investigação. $\mathrm{O}$ método delineado em EE I 6, portanto, deve tornar claras opiniões reputáveis sobre a felicidade.

A primeira aplicação manifesta do método ocorre em EE I 7, que se inicia com uma referência explícita ao método exposto no capítulo anterior: uma vez encerrado o proêmio, cabe buscar descobrir com precisão o que é a eudaimonia a partir de pontos de partida que não são suficientemente claros. Tais pontos de partida foram caracterizados em EE I 6 como phainomena e, em EE I 7, tem-se uma clara indicação da correção da interpretação de

8 Trata-se, não por acaso, de um trecho inserido no conjunto dos livros comuns entre a Ética Nicomaqueia e a Ética Eudêmia. 
Owen, uma vez que a investigação parte de uma opinião introduzida como crença aceita (homologeitai, 1217a21). Trata-se, na verdade, de um endoxon muito básico sobre a felicidade, cujo exame ocupa adequadamente o início da investigação propriamente dita, a saber:

[F] A felicidade é "o maior e o melhor dos bens humanos". (1217a21)

Uma vez que o exame dessa opinião ocorre no primeiro momento da investigação propriamente dita, ele deverá desenvolver-se sem depender de qualquer elemento estabelecido em EE I 1-5, se estiver correta a hipótese da inteira independência entre a investigação e o proêmio. Pretendemos verificar se essa hipótese resiste a um exame do argumento de EE I 7.

\section{O ARGUMENTO DE EE I 7}

Após apresentar a opinião que será discutida em EE I 7, o restante do capítulo opera uma restrição sobre a amplitude do conjunto dos bens no interior do qual se encontra a eudaimonia 9 . Ao final do exame, a felicidade não mais permanecerá caracterizada de modo vago como o melhor dos bens humanos em geral, mas será localizada no conjunto dos bens que são realizáveis para o homem ${ }^{10}$. Tal como fora avançado na exposição do método, a investigação dota de precisão a apresentação do que havia de verdadeiro no phainomenon. De fato, a afirmação verdadeira (mas imprecisa) segundo a qual a felicidade é o maior e o melhor dos bens humanos é compatível com

\footnotetext{
9 O movimento de restrição que caracteriza o argumento de EE I 7 é detalhadamente examinado por Dirlmeier (1969, 190-193) e Buddensiek (1999, 68-76).

10 dêlon hoti kai tên eudaimonian tôn anthrôpô(i) praktôn ariston theteon (1217a40).
} 
afirmações que identifiquem incorretamente a felicidade com bens irrealizáveis para o ser humano. Um investigador que partisse de $[F]$, mas interpretasse a felicidade como bem irrealizável, teria logo no início da pesquisa tomado um rumo equivocado e seus resultados estariam, assim, comprometidos. O progresso da investigação, portanto, depende da correta localização da felicidade entre os bens humanos.

O princípio metodológico de partir de phainomena pouco claros e progredir em direção à expressão precisa da verdade que neles está contida é uma instância do princípio geral que impõe partir do que é mais cognoscível para nós e buscar o que é mais cognoscível por si. Tratando desse princípio geral, Suzanne Mansion (1979) observou que a passagem ao mais cognoscível por si, em certas ocasiões, corresponde à passagem de uma apreensão geral e vaga de um certo $x$ para uma apreensão precisa que se estabelece a partir da identificação das distinções necessárias ${ }^{11}$. Segundo Mansion, a apreensão inicial e vaga de $x$ pode, em alguns casos, ser ilustrada pela compreensão que uma criança tem de uma palavra que é, por vezes, apreendida de modo tão vago, que acaba por ser aplicada a itens aos quais não cabe sua aplicação. $O$ exemplo que ilustra o ponto é retirado do início da Física (ver 184b12-14), onde Aristóteles recorre ao suposto fato que crianças inicialmente empregam a palavra

11 Ao discutir o modo como Aristóteles apresenta o princípio metodológico geral no início de Física I, a autora faz o seguinte comentário: "...o nosso conhecimento começa a partir de uma apreensão global dos objetos submetidos à nossa experiência, apreensão que deve ser tornada precisa em seguida, fazendo-se as distinções necessárias na massa confusa de dados. Que um tal movimento seja caracterizado como passagem do geral ao particular pode ser compreendido, sob a condição de pensar que Aristóteles não fala, aqui, da passagem de um conceito genérico simples, aos conceitos específicos mais particulares e mais complexos, mas fala, antes, da visada englobante de um todo percebido confusamente, no qual se deve distinguir elementos e princípios..." (MANSION 1979, 165). 
"pai" para fazer referência a todos os homens e a palavra "mãe" para fazer referência a todas as mulheres. A passagem para o mais cognoscível por si ocorreria quando as crianças passam a distinguir, entre os homens, aquele ao qual cabe chamar de "pai" e, entre as mulheres, aquela que é "mãe". Ora, o trajeto cumprido em EE I 7 segue o mesmo caminho: parte-se de uma apreensão inicial do sentido de "eudaimonia" que, de tão vaga, permite a aplicação do termo ao que não deve ser assim denominado. Ao final do percurso, a apreensão do phainomenon foi fortalecida pela incorporação de distinções que impedirão ao menos algumas das aplicações incorretas do termo.

$\bigcirc$ movimento de restrição do conjunto dos bens no qual se encontra a felicidade surge logo no início do capítulo, quando Aristóteles enfatiza que já a formulação de [F] contém uma restrição ao âmbito dos bens humanos. Não estão em questão os bens exclusivos aos deuses nem tampouco os bens que alcançam os demais animais (1217a21-29).

Tomando por certo que a felicidade é o maior e o melhor dos bens humanos, Aristóteles apresenta um argumento com vistas a mostrar que "se deve tomar a felicidade como a melhor das coisas realizáveis para o homem" (1217a39). O resultado final estabelece que o melhor dos bens humanos pertence a uma categoria específica dos bens humanos, a saber, os realizáveis para o homem.

$\mathrm{O}$ argumento, tal como apresentado por Aristóteles, comporta as seguintes duas partes distintas:

[1] Falemos agora que, dos bens, 1.a) alguns são realizáveis para o homem, ao passo que 1.b) outros não são realizáveis. Dizemos isso desse modo porque 1.b.1) alguns dos seres em nada participam da 
mudança, de modo que tampouco participam dos bens realizáveis. ${ }^{12}$ 1.b.2) Algumas coisas, por outro lado, são realizáveis, mas realizáveis para os que são mais poderosos do que nós. (1217a30-35)

[2] Uma vez que o realizável é dito de dois modos (pois participam da ação tanto 2.a.1) as coisas em vista das quais agimos, como 2.a.2) as que fazemos em vista delas [toutôn heneka], por exemplo, consideramos entre os realizáveis a saúde e a riqueza, assim como as coisas que fazemos em vista [charin] delas, as saudáveis e as que concernem à aquisição de riquezas), é evidente 2.b) que se deve estabelecer a felicidade como a melhor das coisas realizáveis para o homem. (1217a35-40)

No trecho [1], Aristóteles divide os bens entre 1.a) os que são e 1.b) os que não são realizáveis para o homem, dividindo, em seguida, a segunda categoria entre 1.b.1) os bens não realizáveis em absoluto e 1.b.2) os que são realizáveis para os seres que são mais poderosos do que nós. A introdução da categoria 1.b.1) mostra que a investigação acerca da felicidade não pode pautar-se pelo estudo do bem tomado em geral. O bem tomado em geral inclui até mesmo o bem que se encontra nos seres imutáveis, que não são de modo algum realizáveis. Esses bens devem estar fora do âmbito do estudo proposto, uma vez que não seria possível tomá-los como bens humanos em qualquer sentido razoável ${ }^{13}$.

\footnotetext{
12 Nos manuscritos, lê-se hôst' oude tôn agathôn em 1217a33. Mantida a lição dos manuscritos, o texto de 1.b.1) corresponderia ao seguinte: "alguns dos seres em nada participam da mudança, de modo que tampouco o fazem alguns dos bens". A lição dos manuscritos é retida no texto de Susemihl e nas traduções de Dirlmeier, Inwood/Woolf e Kenny. Como notou D. J. Allan (1971), no entanto, lida desse modo, a sentença contém uma inferência problemática que parte de "alguns dos seres não participam da mudança" e conclui (hôste) "alguns dos bens não participam da mudança”. Diante disso, seguimos Walzer/Mingay e adotamos a conjectura de Russell para 1217a33: hôst' oude <prak> tôn agathôn).

13 Em EE I 8, 1218a15-21, Aristóteles menciona um argumento que tentaria mostrar a partir do suposto fato que o um em si é bom, que são bens a justiça e a saúde. Mesmo no âmbito de um tal raciocínio, correspondem aos bens humanos a saúde e a justiça. $\mathrm{O}$ um em si, ainda que seja tomado como fonte a partir da qual são bens os bens humanos, não pode, ele próprio, ser considerado um bem humano.
} 
Por outro lado, a introdução da categoria 1.b.2), dos bens "realizáveis para os que são mais poderosos do que nós”, indica que a eliminação dos bens não-realizáveis não faz coincidirem os bens humanos com a categoria 1.a), dos bens realizáveis para o homem. No grupo dos bens do tipo 1.b.2), afinal, seria possível incluir bens humanos, como as benesses que os homens recebem por favor divino. A felicidade, o maior dos bens humanos, estaria nesse conjunto, se estivessem corretas as opiniões dos que a compreendem como resultado de possessão ou inspiração divina (EE I 1, 1214b23).

O passo decisivo para nossa discussão encontra-se no trecho [2] do argumento. De acordo com a leitura mais imediata do texto, a felicidade é incluída no domínio das coisas realizáveis a partir da introdução de uma duplicidade de sentidos para o termo "realizável" (prakton) ${ }^{14}$. Aristóteles afirmaria que o "realizável" é dito de dois modos - e disso concluiria que a felicidade deve ser tomada como a melhor das coisas realizáveis para o homem.

Os dois sentidos pelo qual algo é dito ser um bem realizável são apresentados na observação parentética de 1217a36-39. Aristóteles, ali, apresenta uma distinção entre dois modos pelos quais algo "participa da ação" (metechei praxeôs). Essa expressão indica o que é realizável para o homem, dado que, ao ilustrar os modos pelos quais algo participa da ação, Aristóteles afirma, acerca de cada um dos exemplos, que tithemen tôn praktôn, "consideramos entre os realizáveis". Desse modo, conclui-se que é dito ser "realizável" 2.a.1) aquilo em vista do que se faz algo ou

14 Um exame compreensivo das possibilidades de tradução do termo pode ser encontrado em Buddensiek (1999, 73-74). 
2.a.2) aquilo que se faz com vistas a um item do tipo 2.a.1). A passagem da distinção introduzida em 2.a) para a conclusão expressa em 2.b) não costuma atrair a atenção dos intérpretes. Ela não recebe comentários nas breves reconstruções de Kenny $(1978,197)$ e Rowe $(1971,20)$ ao passo que Woods ([1982] 1992, 60) limita-se a comentar a distinção apresentada em 2.a) sem fazer menção à passagem para 2.b). Uma postura diferente encontra-se em Buddensiek (1999, 74-75), que expressa desconforto com aquela que qualificamos como a leitura mais direta do texto. Como ele observa, da distinção entre os usos de prakton, nada se segue acerca da eudaimonia - em especial, não se segue que ela se encontre no âmbito do realizável.

De fato, é curioso que, tão logo tenha apresentado a distinção entre 2.a.1) e 2.a.2), Aristóteles considere que estão asseguradas as condições para o estabelecimento da conclusão expressa em 2.b), segundo a qual a felicidade está entre as coisas realizáveis para o homem. Uma vez aceita a distinção expressa em 2.a.1) e 2.a.2), no entanto, o estabelecimento do resultado depende da aceitação de uma premissa adicional singela, mas nada trivial: a inclusão da felicidade em uma das duas categorias que esgotam o que participa da ação.

Todo estudante neófito da ética aristotélica aprende, logo no início dos seus estudos, que a felicidade deve ser tomada como um fim com vistas ao qual são praticadas todas as ações do agente. Evidentemente, é por ser um fim que a felicidade qualifica-se como realizável, entrando na categoria 2.a.1). O resultado do argumento de EE I 7, portanto, apoia-se nesta, que é uma das teses mais básicas da ética aristotélica:

[T] A felicidade é um fim com vistas ao qual o agente 
executa suas ações ${ }^{15}$.

No texto examinado, Aristóteles pode substituir a caracterização vaga da felicidade como o melhor dos bens humanos $[\mathrm{F}]$ pela caracterização mais precisa que a toma como o melhor dos bens realizáveis para o homem porque está supondo que a felicidade deva ser compreendida como um fim. $O$ modo como essa suposição ingressa no texto é relevante para a nossa questão e, para esclarecê-lo, é útil lançar mão de uma breve comparação com a Ética Nicomaqueia.

Quando se apresenta ao aluno iniciante a tese segundo a qual a felicidade é um fim, o passo seguinte da exposição corresponde a introduzir o estudante ao debate acerca de como Aristóteles pretenderia fundamentar essa tese na EN. Apesar da falta de consenso em torno do assunto, costumase identificar na EN a apresentação de um argumento em favor dessa tese fundamental ${ }^{16}$. Nada semelhante ao que se encontra na EN a esse respeito, no entanto, é visto na Ética Eudêmia - em particular, não há nada que se possa tomar como um argumento em favor dessa tese nos textos que precedem EE I $7^{17}$, nos quais Aristóteles poderia estar tomando apoio para estabelecer o resultado expresso em 2.c).

15 Para o argumento em questão, é irrelevante que a felicidade seja o fim último. Basta que ela seja tomada como um, entre outros fins, para que ocorra sua inclusão na categoria distinguida em 2.a.1) e para que, desse modo, esteja assegurado o resultado do argumento.

16 O locus classicus da discussão está em EN I 1, 1094a18-24 e a literatura básica sobre o tema inclui Geach (1958), Hardie (1965 e [1968] 1980), Ackrill (1974) e Broadie (1991). A despeito da grande quantidade de trabalhos sobre o tema, a discussão está longe de ter-se esgotado, como bem se percebe a partir de Gazoni (2012).

17 Os intérpretes costumam apontar EE I 8, 1218a38-b12 como estabelecendo a partir de um argumento por eliminação que o maior dos bens deve ser identificado com "o em vista de tomado como fim" [to hou heneka hôs telos] (ver, por exemplo, ROWE 1971, 20). Acreditamos que essa interpretação seja problemática pelas razões que expusemos em ZILLIG 2012. De qualquer modo, a suposta defesa da tese ocorre após EE I 7. 
A despeito, contudo, de não haver um argumento em favor dessa tese que permitiria justificar a passagem de 2.a.1) e 2.a.2) para 2.b), a tese, ela mesma, está claramente expressa no início de EE I 2, onde Aristóteles afirma que todo aquele capaz de viver segundo a sua própria escolha "estabelece algum alvo do viver belamente (...) visando o qual executará todas as ações (já que não ordenar a vida em direção a algum fim é sinal de muita estupidez)" (1214b611). Aristóteles, portanto, deve estar tomando apoio nessa passagem, quando expõe a distinção que esgota o âmbito do realizável e salta para a conclusão segundo a qual a felicidade conta-se entre as coisas realizáveis para o homem. Dado que a felicidade já fora tomada como um fim, basta mostrar que os fins fazem parte do âmbito do realizável para, então, estabelecer que a felicidade é realizável.

$\mathrm{O}$ andamento do argumento exposto nos trechos [1] e [2], portanto, mostra que em EE I 7 Aristóteles está tomando como certa uma tese que fora introduzida, mas não defendida, em EE I 2. Esse quadro sugere que, nos textos que nos ocupam, a tese segundo a qual a felicidade é um fim está sendo tomada como um endoxon, a mesmo título do que $[\mathrm{F}]$.

Esse resultado certamente não é capaz de fornecer uma resposta definitiva para a questão posta acerca da relação entre o proêmio e o argumentação central da EE. No entanto, ele fortalece a hipótese que encontra um vínculo de dependência da investigação propriamente dita em relação ao proêmio. Se a reconstrução proposta para EE I 7 estiver correta, logo no início da porção investigativa do tratado, Aristóteles apresenta um argumento que toma como premissa uma opinião que fora introduzida no proêmio. Desse modo, ao menos com relação a EE I 7, haveria uma 
estreita relação de dependência entre o argumento desenvolvido e o que fora apresentado no proêmio.

Cabe também notar que, se for possível tomar [T] como endoxon introduzido em EE I 2, o procedimento de Aristóteles no texto que nos ocupa conforma-se, em linhas gerais, ao método que Aristóteles adota para o esclarecimento das endoxa. Esse método é brevemente descrito em uma muito citada passagem de Ética Nicomaqueia VII 1 (texto comum à Ética Eudêmia, que deve ser lido em conjunto com EE I 6) ${ }^{18}$. Em 1147b2-7, Aristóteles estabelece que, estando de posse dos phainomena relevantes, o pesquisador deve "percorrer as dificuldades" (diaporein) suscitadas pelas endoxa. O procedimento encerrase quando são "solucionadas as dificuldades", permanecendo as endoxa.

Tipicamente, uma investigação que se apoia em endoxa dá-se a partir de um exame cruzado de diferentes opiniões sobre o mesmo assunto. Esse exame cruzado revela as dificuldades sobre o tema, uma vez que surgem inconsistências entre as opiniões ${ }^{19}$. Em EE I 7, não há um confronto explícito entre $[\mathrm{F}]$ e $[\mathrm{T}]$ - e, de fato, o capítulo não sugere que haja uma inconsistência inicial entre essas opiniões que deva ser solucionada a partir de um ajuste fino na interpretação de tais afirmações. No entanto, uma vez solucionadas as dificuldades, diz Aristóteles, devem permanecer, se não todas as opiniões, ao menos a maioria delas e, sobretudo, as mais fundamentais (ta kuriôtata: EN, 1145b5). Ora, ao final de I 7, Aristóteles estabeleceu as

18 Ver também EE VII 1, 1235b13-18.

$19 \mathrm{Em}$ nenhum texto essa característica do método é mais evidente do que no livro B da Metafísica. Lá, as incompatibilidades entre as diferentes opiniões são descritas como "nós" que devem ser desatados pelos que pretendem progredir na investigação (ver 995a29-30) 
condições a partir das quais [F] e [T] podem ser conjuntamente afirmadas. Para que o alvo com vistas ao qual o agente executa todas as suas ações possa ser identificado com o maior dos bens humanos, é fundamental que esse último esteja situado no âmbito dos bens realizáveis pela ação humana. Se o maior dos bens fosse tomado como correspondendo à Ideia de Bem ou ao bem comum (como teriam feito os platônicos), seria impossível sustentar conjuntamente [F] e [T], uma vez que o maior dos bens fugiria ao que pode ser tomado como fim pelo agente humano. De fato, se em EE I 7 Aristóteles não está tentando desfazer uma inconsistência entre opiniões, ele está impedindo o surgimento da inconsistência que consistiria na adoção conjunta de [T] e da compreensão platônica do maior dos bens. Desse modo, o procedimento de Aristóteles em EE I 7 pode ser compreendido como uma tentativa de preservar a coerência entre duas opiniões que seriam fundamentais à compreensão do felicidade.

Convém ressaltar que a pretensão de preservar as opiniões fundamentais é clara na descrição metodológica de EN VII 1. No método proposto, uma prova satisfatória (dedeigmenon an eiê hikanôs, 1147b7) é obtida quando, tendo sido solucionadas as dificuldades, restarem as endoxa (a saber, a maioria ou as mais fundamentais). Tudo se passa como se, tendo em vista o caráter fundamental de [F] e [T], Aristóteles tenha decidido começar a investigação rigorosa acerca da felicidade assegurando as condições nas quais mantém-se a coerência entre tais opiniões.

Considerações finais

Nas seções anteriores, procuramos, em primeiro lugar, assinalar a dependência do argumento de EE I 7,1217a3040 em relação à opinião [T], que não é expressa em EE I 7. 
Em segundo lugar, notamos que, ao contrário do que ocorre na EN, essa opinião não é, na $\mathrm{EE}$, acompanhada de uma argumentação, sendo introduzida sem EE I 2 sem qualquer fundamentação. A partir disso, sugerimos que, na $\mathrm{EE}$, a opinião $[\mathrm{T}]$ tem caráter de endoxon. Tal sugestão obtém algum apoio do fato que, se [F] e [T] forem tomados como endoxa, o procedimento de Aristóteles em EE I 7 conforma-se ao que se prescreve para o tratamento de endoxa em passagens-chave como EN VII 1, 1147b2-7. Esse resultado, como sustentamos, sugere que não há uma estrita independência dos argumentos apresentados na parte investigativa da EE em relação ao proêmio.

Cabe, finalmente, observar que o resultado estabelecido acerca de EE I 7 pode fornecer elementos importantes para uma comparação entre os métodos adotados na EE e na EN. Se a interpretação que propusemos está correta, o argumento de EE I 7 parte da aceitação de [T] e [F], que são tomadas como endoxa. Em Tópicos I 1, o argumento dialético é, justamente, apresentado como tendo endoxa na posição de premissas (100a29-30). Assim, ao menos com relação à natureza do que se toma como ponto de partida, nossa interpretação de EE I 7 sugere que a argumentação ali exposta é de caráter dialético.

Tradicionalmente, a dialética é tomada como o método da ética aristotélica em geral. A Ética Eudêmia e a Nicomaqueia costumam ser indistintamente caracterizadas como obras de natureza dialética ${ }^{20}$. $O$ ponto que apresentamos, no entanto, indica que essa opinião deve ser

\footnotetext{
20 Isso pode ser visto, por exemplo, nas obras de Stewart (1892, vol. 2, p. 120) e Burnet (1900, p. xvii), cuja influência contribuiu para a difusão da posição segundo a qual a ética aristotélica é essencialmente de caráter dialético.
} 
matizada. Em nossa reconstrução, o argumento de EE I 7 é rigorosamente dialético quanto à natureza das premissas. Esse argumento não encontra paralelo na $\mathrm{EN}$, onde, por sua vez, Aristóteles não se contenta com a introdução de [T] como mero endoxon. Isso sugere que, ao menos em alguns casos, a EE toma a argumentação dialética apresentada no início dos Tópicos como método apropriado à ética, ao passo que a EN não o faz ${ }^{21}$.

Abstract: Aristotle's research on happiness in the Eudemian Ethics has its proper start at EE I 7, as the first six chapters of the book are described as a preamble. This being so, a question arises about the kind of relation that obtains between the preamble and the main text. Is the preamble a mere introduction to the research, or is it possible that the arguments developed in the research of the EE depend on what has been presented in the preamble? We believe that an analysis of the argument put forward in EE I 7 may shed some light on the question. We will sustain that this argument at least takes one of its premises from the preamble and so cannot proceed without relying on what has been presented in the introduction of the text.

Keywords: Aristotle; method; happiness; telos.

\section{REFERÊNCIAS}

\section{EDIÇÕES E TRADUÇÕES DAS OBRAS DE ARISTÓTELES}

\section{BYWATER, I. Ethica Nicomachea. Oxford: Clarendon, 1942.}

INWOOD, B.; WOOLF, R. Eudemian Ethics. Cambridge: Cambridge U. P. 2013.

JAEGER,W. Metaphysica. Oxford: Clarendon, 1957.

21 Marco Zingano (2007) defendeu, contrariamente à posição tradicional, que o caráter dialético aplica-se antes ao método adotado pela EE, do que ao método da EN. Evidentemente, não desejamos com isso sugerir que Zingano adote nossa leitura de EE I 7. 
KENNY, A. The Eudemian Ethics. Oxford: Oxford U. P., 2011.

ROSS, W. D. Ethica Nicomachea. In: . The works of Aristotle translated into english, vol. IX. Oxford: Clarendon, 1925.

. Physics. Oxford: Clarendon, 1936.

- Aristotle's Prior and Posterior Analytics. Oxford: Clarendon, 1949 1958.

- Topica et Sophistici Elenchi. Oxford: Clarendon, . Ars Rhetorica. Oxford: Clarendon, 1959.

SUSEMIHL, F. Eudemi Rhodii Ethica. Berlim: Teubner, 1884.

WALZER, R. R.; MINGAY, J. M. Ethica Eudemia. Oxford: Clarendon, 1991.

\section{DEMAIS OBRAS}

ACKRILL, J. L. Aristotle on eudaimonia. Proceedings of the British Academy v. 60, p. 339-359, 1974.

ALLAN, D. J. The fine and the good in Eudemian Ethics. In MORAUX, P.; HARLFINGER, D. Untersuchungen zur Eudemischen Ethik. Berlin: Walter de Gruyter, 1971, p. 6371.

BROADIE, S. Ethics with Aristotle. Oxford: Oxford U. P. 1991.

BUDDENSIEK, F. Die Theorie des Glücks in Aristoteles' 
Eudemischer Ethik. Göttingen: Vandenhoeck und Ruprecht, 1999.

BURNET, J. The ethics of Aristotle. London: Methuen, 1900.

CLEARY, J. "Phainomena in Aristotle's methodology. International Journal of Philosophical Studies, 2: 1, 1994.

DIRLMEIER, F. Eudemische Ethik. Berlin: AkademieVerlag, 1969.

COOPER, J. M. Reason and human good in Aristotle. Indianapolis: Hackett, 1975.

GAZONI, F. Felicidade controversa - Volição, prescrição e lógica na eudaimonia aristotélica. 2012. 220 p. Tese (Doutorado em Filosofia) - Universidade de São Paulo, São Paulo, 2012.

GEACH, P. T. History of a fallacy. Journal of the philosophical association, v. 5, n. 19-20, 1958.

GIGON, O. Das Prooimion der EE. In MORAUX, P.; HARLFINGER, D. Untersuchungen zur Eudemischen Ethik. Berlin: Walter de Gruyter, 1971, p. 93-133.

HARDIE, W. F. R. The final good in Aristotle's ethics. Philosophy, v. XL, p. 277-295, 1965

. Aristotle's ethical theory. Oxford: Clarendon, [1968] 1980.

IRWIN, T. "Ways to first principles: Aristotle's methods of discovery”. Philosophical Topics, v. XV, n. 2, 1987.

JAEGER, W. Aristotle - Fundamentals of the history of his 
development. Oxford: Clarendon, 1948.

KENNY, A. The aristotelian ethics. Oxford: Oxford U. P. 1978.

MANSION, S. "Plus connu en soi", "plus connu pour nous". Une distinction epistemologique importante chez Aristote. Pensamiento, v. 35, p. 161-170, 1979.

NUSSBAUM, M. The Fragility of Goodness. Cambridge, Cambridge U. P. 1986.

OWEN, G. E. L. Tithenai ta phainomena. In: MANSION, S. Aristote et les probèmes de méthode. Louvain: Publications Universitaires de Louvain, 1961, p. 83-103.

ROWE, C. J. The Eudemian and Nicomachean Ethics: a study in the development of Aristotle's thought. Proceeding of the Cambridge Philological Society, Supplement 3, 1971.

STEWART, J. A. Notes on the Nicomachean Ethics of Aristotle. Oxford: Clarendon, 1892.

WIANS, W. “Saving Aristotle from Nussbaum's Phainomena. In: PREUS, A.; ANTON, J. P. Essays in Greek Philosophy v. V - Aristotle's Ontology. Albany, State University of New York Press, 1992.

WOODS, M. Eudemian Ethics - Books I, II and VIII. Oxford: Clarendon, [1982] 1992.

ZILLIG, R. "O 'melhor' no âmbito da ação humana - Ética Eudêmia I 8”. Dissertatio, v. 36, 2012, p. 299-316.

ZINGANO, M. "Aristotle and the problems of method in ethics". Oxford Studies in Ancient Philosophy, v. xxxii, p. 
297-330, 2007. 